\title{
Élise Rajchenbach-Telles, «Mais devant tous est le Lyon marchant». Construction littéraire d'un milieu éditorial et livres de poésie française à Lyon (1536-1551)
}

\section{Maurizio Busca}

\section{(2) OpenEdition \\ Journals}

\section{Edizione digitale}

URL: https://journals.openedition.org/studifrancesi/21071

DOI: $10.4000 /$ studifrancesi. 21071

ISSN: 2421-5856

\section{Editore}

Rosenberg \& Sellier

\section{Edizione cartacea}

Data di pubblicazione: 1 décembre 2019

Paginazione: $562-563$

ISSN: 0039-2944

\section{Notizia bibliografica digitale}

Maurizio Busca, «Élise Rajchenbach-Telles, «Mais devant tous est le Lyon marchant». Construction littéraire d'un milieu éditorial et livres de poésie française à Lyon (1536-1551)», Studi Francesi [Online], 189 (LXIII | III) | 2019, online dal 01 mars 2020, consultato il 11 novembre 2021. URL: http://

journals.openedition.org/studifrancesi/21071 ; DOI: https://doi.org/10.4000/studifrancesi.21071

Questo documento è stato generato automaticamente il 11 novembre 2021.

\section{cc) $(8)$}

Studi Francesi è distribuita con Licenza Creative Commons Attribuzione - Non commerciale - Non opere derivate 4.0 Internazionale. 


\title{
Élise Rajchenbach-Telles, «Mais devant tous est le Lyon marchant». Construction littéraire d'un milieu éditorial et livres de poésie française à Lyon (1536-1551)
}

\author{
Maurizio Busca
}

\section{NOTIZIA}

Élise Rajchenbach-Telles, «Mais devant tous est le Lyon marchant». Construction littéraire d'un milieu éditorial et livres de poésie française à Lyon (1536-1551), Genève, Droz, 2016, «Travaux d'Humanisme et Renaissance» 560, pp. 597.

1 Élise Rajchenbach-Teller, attualmente impegnata in un progetto di edizione digitale delle opere di Charles Fontaine, è autrice di numerosi lavori sulla poesia lionese del Cinquecento centrale e sui rapporti fra i diversi attori coinvolti nel campo dell'edizione di opere poetiche: autori, traduttori, editori, stampatori e altre figure di collaboratori. Il presente volume costituisce l'esito di ricerche avviate nell'ambito di una tesi dottorale sull'ambiente letterario e editoriale nella Lione degli anni 1536-1551 e sul processo di elaborazione, produzione e ricezione dei libri di poesia, ricerche che qui integrano i risultati di studi più recenti e pongono nuove basi per sviluppi ulteriori. L'arco temporale preso in esame dall'A. corrisponde a un quindicennio di grande vivacità, durante il quale si assiste a sperimentazioni e trasformazioni fondamentali per quanto riguarda sia la produzione poetica francese (non soltanto lionese) sia i supporti materiali che la accolgono: i due estremi cronologici corrispondono alla pubblicazione della raccolta franco-latina di Dolet per la morte del Delfino (1536), che federa in un unico libro i principali poeti dell'epoca legati al mondo editoriale lionese, e alla 
pubblicazione del Quintil horatian (1551), che attesta l'emergere della Brigade ronsardiana nel panorama letterario nazionale e l'imporsi di Parigi su Lione come maggior centro di produzione letteraria di Francia.

2 La prima parte del volume («La promotion du livre de poésie vernaculaire à Lyon. Promuovoir une langue», pp. 31-191) è dedicata al lavoro di alcuni dei maggiori editori lionesi degli anni Trenta e Quaranta del Cinquecento: Étienne Dolet, François Juste, Jean de Tournes e Guillaume Rouillé. Di questi quattro editori, di cui è ben noto il ruolo di promotori della letteratura in lingua francese, sono presentate le reti di collaboratori (fra i quali si segnalano i nomi di Barthélemy Aneau, Charles Fontaine, Antoine Du Moulin e Denis Sauvage), le strategie editoriali e commerciali, le modalità di appropriazione di opere e di modelli italiani e le pratiche di «mise en livre» di testi poetici. Viene così ricostruito il contesto che rende possibile il fiorire della poesia vernacolare - e del libro di poesia vernacolare - nella Lione del primo Rinascimento. Nella seconda parte («L'invention d'un champ littéraire à Lyon», pp. 195-318) l'A. si interessa alle dinamiche del campo letterario lionese, giungendo a rimettere in questione l'esistenza di una «scuola» poetica locale. Se i legami fra gli autori lionesi vengono spesso esibiti dagli editori e dagli autori stessi, appare problematico ricondurre le diverse esperienze a una autentica coerenza d'insieme. Emerge, invece, l'impegno di editori e uomini di lettere teso alla promozione di Lione quale capitale poetica francese: questa operazione si concretizza non soltanto nelle varie rappresentazioni del rapporto di sodalitas che unisce i poeti legati alla città, ma anche attraverso l'appropriazione, da parte degli editori, di grandi autori forestieri come Jean Lemaire de Belges e Clément Marot. Mancano tuttavia sia un programma strutturato e largamente condiviso, sia un capofila: il caso di Scève, che in seguito alla pubblicazione di Delie viene meno alle attese del suo editore De Tournes, è in questo senso emblematico. L'A. riconosce piuttosto nel ruolo preminente delle figure femminili (autrici, promotrici o destinatarie di opere poetiche) un fattore caratterizzante del contesto lionese. La terza e ultima parte del volume («Esquisse de géographie du livre de poésie lyonnais», pp. 319-443) analizza i rapporti fra editoria lionese, tolosana e parigina per rilevare le peculiarità del libro di poesia lionese rispetto alla produzione degli altri due principali centri di produzione libraria dell'epoca. Se Tolosa intrattiene rapporti di collaborazione subordinata con Lione, che dispone di risorse sensibilmente superiori, Parigi si pone, al contrario, come un centro concorrente. La rivalità fra le due città vede inizialmente Lione in posizione di vantaggio, anche grazie alla sua situazione geografica e commerciale estremamente favorevole; a partire dagli anni Cinquanta, quando Parigi comincerà ad imporsi, gli editori lionesi tenteranno di riaffermarsi sul mercato nazionale attraverso il ricorso alle strategie che si erano dimostrate vincenti nel corso del decennio precedente.

In conclusione, segnaliamo la presenza di corpose appendici (pp. 457-528) e di una ricca bibliografia (pp. 529-579). 